\title{
Genotoxic Risks to Nurses from Contamination of the Work Environment with Antineoplastic Drugs in Japan
}

\author{
Jin Yoshida, Hiroshi Kosaka, Kimiko Tomioka and Shinji Kumagai \\ Department of Environmental Health, Osaka Prefectural Institute of Public Health, Japan
}

\begin{abstract}
Genotoxic Risks to Nurses from Contamination of the Work Environment with Antineoplastic Drugs in Japan: Jin Yoshida, et al. Department of Environmental Health, Osaka Prefectural Institute of Public Health-The aims of the present study were to clarify the work environment contamination by antineoplastic drugs in a hospital ward and to assess the genotoxic risks to nurses who routinely handle antineoplastic drugs in Japan. The exposed group consisted of 19 female nurses who routinely handled antineoplastic drugs. The control group consisted of 18 female nurses who did not handle antineoplastic drugs in the same hospital as the exposed group. The genotoxicity of the 19 antineoplastic drugs used in the hospital ward and 8 wipe samples of the workbench after handling of antineoplastic drugs were measured using the umu assay. Lymphocyte DNA damage (tail length) was measured with alkaline methods of the single cell gel electrophoresis assay (comet assay). Of the 19 antineoplastic drugs, dacarbazine, bleomycin, daunorubicin, doxorubicin, pirarubicin, carboplatin, cisplatin and etoposide induced genotoxicity. Of the 8 sampling $\mathrm{d}$, the umu activity of the wipe sample was positive on $3 \mathrm{~d}$. Contamination of the workbench was found when the nurses handled more drugs than on other days. The medians of the tail length in the comet assay were 8.5 and $5.1 \mu \mathrm{m}$, respectively, for the exposed and control groups, with a significant difference ( $p=0.004$ by Mann-Whitney's U-test). In the present study, the nurses of the exposed group were considered to have been exposed to antineoplastic drugs and lymphocyte DNA damage of the exposed group was suggested to be induced by antineoplastic drugs.
\end{abstract}

(J Occup Health 2006; 48: 517-522)

Received May 16, 2006; Accepted Jul 31, 2006

Correspondence to: J. Yoshida, Department of Environmental Health, Osaka Prefectural Institute of Public Health, 1-3-69 Nakamichi, Higashinari-ku, Osaka 537-0025, Japan

(e-mail:jnyosida@iph.pref.osaka.jp)
Key words: Antineoplastic drug, Nurse, Work environment contamination, Genotoxicity, Lymphocyte DNA damage

Antineoplastic drugs, used to treat patients in hospitals, can be divided into the following groups based on their actions on tumor cells: alkylating drugs, antibiotics, metabolic antagonists, plant alkaloids, DNA chelators, hormones and enzymes ${ }^{1-3)}$. Some antineoplastic drugs are known to induce cytotoxicity, genotoxicity and carcinogenicity $^{4,5)}$. Antineoplastic drugs are clearly beneficial for patients but there is concern about their health risk, especially genotoxic risk, to the hospital personnel handling them ${ }^{6}$. Increases in urinary mutagenicity, chromosomal aberrations, sister chromatid exchanges and DNA strand break have been observed among hospital personnel handling antineoplastic drugs ${ }^{7-11}$. On the other hand, no increase in their cytogenetic effect has been observed $^{12-14)}$. Evaluation of exposure to antineoplastic drugs and their genotoxic risk to hospital personnel is important to prevent genotoxicity and possible carcinogenicity.

In Japan, guidelines for handling antineoplastic drugs in the hospital were issued by the Japan Pharmaceutical Association in $1991^{15)}$. Isii et al. reported that in a survey of 313 hospitals in Japan, $40 \%$ of the nurses were not at all aware of the potential adverse effects of occupational exposure to antineoplastic drugs, and $61 \%$ did not take protective countermeasures against antineoplastic drugs ${ }^{16)}$. Moreover, there has been no report on the work environment contamination by antineoplastic drugs and the genotoxic risk posed by it to hospital personnel in Japan.

The aims of the present study were to clarify the work environment contamination by antineoplastic drugs and to assess the genotoxic risk posed by it to hospital personnel in Japan. First, the genotoxicity of antineoplastic drugs used in the hospital ward was measured by the umu assay. The umu assay was developed by Oda et al. for the detection of environmental mutagens and carcinogens, and this assay 
system is useful because of its sensitivity to various chemicals and its ease of use ${ }^{17)}$. Then, to investigate the work environment contamination caused by the handling of antineoplastic drugs, the genotoxicity of wipe samples of the workbench after the handling of antineoplastic drugs was measured by the umu assay. To investigate the genotoxic risk, the lymphocyte DNA damage of the nurses was measured by the single cell gel electrophoresis assay (comet assay). The single cell gel electrophoresis assay was developed by Ostling and Johanson to quantitatively assess DNA damage ${ }^{18)}$. This method is relatively simple, inexpensive and rapid, and is thus suited to the biomonitoring of workers who are exposed to genotoxic hazards. Maluf and Erdtmann reported that when the genotoxic risk to nurses who handled antineoplastic drugs was investigated with cytokinesisblock micronuclei, dicentric bridges and the single cell gel electrophoresis assay in a follow-up study, only the single cell gel electrophoresis assay found a significant difference between the nurses handling antineoplastic drugs and the control group ${ }^{19)}$.

\section{Subjects and Methods}

This study was approved by the ethical review board of the Osaka Prefectural Institute of Public Health.

\section{Subjects}

We selected one hospital in the Kinki area of Japan for this study. The nurses at the departments of hematology and cardiovascular disease in the hospital numbered 19 and 19, respectively. All nurses were female. We recruited 19 nurses who belonged to the Department of Hematology for this study as the exposed group. The nurses of the exposed group had been routinely preparing antineoplastic drugs, e.g., injecting saline into an antineoplastic drug vial and then injecting the solution into an intravenous medical bag. We recruited 19 nurses who belonged to the Department of Cardiovascular Disease for this study as the control group. The nurses of the control group did not handle antineoplastic drugs. After a full written explanation and oral presentation, 19 nurses of the exposed group and 18 nurses of the control group agreed to participate in the present study.

\section{Questionnaire survey}

The nurses were questioned on age, duration of employment, employment experience in roentgenology, smoking and alcohol consumption habits, and present illness or medication.

\section{Measurement of genotoxicity by the umu assay}

Antineoplastic drugs

The genotoxicity of 19 antineoplastic drugs used in the hospital was measured by the $и т и$ assay: alkylating drugs (cyclophosphamide [CAS No. 50-18-0], dacarbazine [CAS No. 4342-03-4] and isophosphamide [CAS No. 3778-73-2]); antibiotics (aclarubicin [CAS No. 57576-44-0], amrubicin [CAS No. 110267-81-7], bleomycin [CAS No. 11056-06-7], daunorubicin [CAS No 20830-81-3], doxorubicin [CAS No. 23214-92-8] and pirarubicin [CAS No. 72496-41-4]); DNA chelators (carboplatin [CAS No. 41575-94-4] and cisplatin [CAS No. 15663-27-1]); plant alkaloids (docetaxel [CAS No. 114977-28-5], etoposide [CAS No. 33419-42-0], irinotecan [CAS No. 97682-44-5], paclitaxel [CAS No. 33069-62-4], vinblastine [CAS No. 865-21-4], vincristine [CAS No. 57-22-7] and vinorelbine [CAS No. 7148622-1]); and anti-CD20 monoclonal antibody (rituximab [CAS No. 174722-31-7]). One hundred microliters of each drug sample solution was assayed.

\section{Wipe sample of the workbench}

The wipe samples were collected on $8 \mathrm{~d}$ during June and July in 2004. A polypropylene sheet was placed on the workbench where the nurses handled the antineoplastic drugs. After use, the sheet was wiped with absorbent cotton wet with $2 \mathrm{ml}$ distilled water. The wipe sample was stored in a polypropylene bottle at $4^{\circ} \mathrm{C}$ until assay. The wipe sample was centrifuged from the absorbent cotton, and then $100 \mu \mathrm{l}$ of the sample was assayed.

\section{Umu assay}

The analytical method has been described in detail by Oda et $a l^{17)}$. Briefly, an overnight cultured Salmonella typhimurium TA1535/pSK1002 was mixed with 100 or $200 \mu \mathrm{l}$ of the sample and phosphate buffered saline (PBS). After incubation for $2 \mathrm{~h}$, the culture mixture was cooled on ice and washed with PBS. The bacterial density was measured as A600 and $\beta$-galactosidase activity was measured using 2-nitrophenyl-beta-D-galactopyraonoside as a substrate. The activity was determined by the method of Miller ${ }^{20)}$. If the umu activity increased in a doseresponse manner, the drug was determined to be genotoxic. The mean background level of the umu gene expression in the absence of an assay substance was 78.1 \pm 1.5 (mean $\pm \mathrm{SD}, \mathrm{n}=10$ ) units, the value of the mean plus 3-times the standard deviation was 82.6 units, and the ratio of the mean plus 3-times the standard deviation to the mean was 1.06 . With respect to the wipe sample, if the $u m u$ activity increased 1.5-fold over the background level, the sample was evaluated to be positive.

\section{Measurement of lymphocyte DNA damage by single cell gel electrophoresis assay}

For the blood sampling, a sample (about $7 \mathrm{ml}$ ) was collected once in a sampling tube containing heparin from each person in the morning in June-July 2004. The blood sample was transported immediately to the laboratory. Lymphocytes isolated from the samples using 
Polymorphprep (Daiichi Pure Chemicals Co. Ltd, Japan), were suspended in PBS. The cell counts and viability were measured by the trypan blue staining method; the cell viabilities of all lymphocyte samples were more than $95 \%$. The lymphocyte samples were adjusted to $2 \times 10^{5} /$ ml with PBS.

The alkaline single cell gel electrophoresis assay was performed with a Comet Assay kit (Trevegen Inc., USA). The sample slide was prepared according to the manual of the kit. Briefly, lymphocyte sample was suspended in molten (at $37^{\circ} \mathrm{C}$ ) low-melt agarose, then the sample was placed on the slide. The slide was placed in a refrigerator until the agarose layer hardened, then the slide was immersed in lysis solution containing $10 \%$ dimethylsulfoxide for $45 \mathrm{~min}$ at $4{ }^{\circ} \mathrm{C}$. After the lysis solution was removed, the slide was immersed in an alkaline solution ( $300 \mathrm{mM} \mathrm{NaOH}, 1 \mathrm{mM}$ EDTA) for 40 min at $25^{\circ} \mathrm{C}$. Then, the slide was placed in an HE-14 electrophoresis bath (TAKARA Co., Japan) and immersed in the alkaline solution. Electrophoresis was carried out for $40 \mathrm{~min}$ at $35 \mathrm{~V}\left(1 \mathrm{~V} \mathrm{~cm}^{-1}\right)$ in a low-temperature room kept at $10^{\circ} \mathrm{C}$. After electrophoresis, the slide was rinsed with distilled water and dried. Analysis was performed after staining with SYBR Green. The slide was evaluated at $200 \times$ magnification under a BX-50 fluorescence microscope with a U-MSWB fluorescence filter (OLYMPUS, Japan). The cells were photographed with a COOLPIX 880 digital camera (Nikon, Japan) attached to the microscope. Tail lengths were measured by Scion Image Beta 4.0.2 (Scion Co., USA) from 100 cells on each slide, their mean value were calculated.

\section{Statistical analysis}

Comparisons of the median values of the two groups were conducted using Mann-Whitney's U-test. Comparisons of the percentages of the two groups were conducted using Fisher's exact test. These calculations were conducted using SPSS 12.0 J software (SPSS Japan Inc, Japan).

\section{Results}

When the 19 antineoplastic drugs used in the hospital ward were examined by the umu assay, dacarbazine, bleomycin, daunorubicin, doxorubicin, pirarubicin, carboplatin, cisplatin and etoposide were identified as genotoxic.

Table 1 shows the results of the umu assay of wipe samples of the workbench after handling the antineoplastic drugs. On the 8 sampling $\mathrm{d}$, the $u m u$ activity (ratio to blank) was higher than 1.5 on the $3 \mathrm{rd}$, 6th and 8th d.

In the present study, no nurses described symptoms induced by the antineoplastic drugs. The characteristics of the exposed group and the control group are presented in Table 2. Comparing between the two groups, the median value of age and duration of employment were not significantly different. The number of smokers, alcohol consumers and the nurses who were undergoing treatment or taking medicine was also not significantly different. Medicines taken by the nurses at the time were iron pills, anti-inflammatory drugs, potassium iodide tablets, anti-allergenic drugs and diuretic drugs. In the exposed group, no nurse had had employment experience in roentgenology, but in the control group, 6 nurses had $(p=0.008)$.

Table 3 shows the results of the single cell gel electrophoresis assay. The medians of the tail lengths were 8.5 and $5.1 \mu \mathrm{m}$ for the exposed and control groups,

Table 1. Genotoxicity of wipe samples from the workbench after the handling of antineoplastic drugs

\begin{tabular}{|c|c|c|c|c|}
\hline $\begin{array}{l}\text { Samplin } \\
\text { day }\end{array}$ & $\begin{array}{l}\text { The antineoplastic drugs handled on } \\
\text { the sampling day (vial number) }\end{array}$ & $\begin{array}{l}\text { er of genotoxic } \\
\left.\text { ials handled }{ }^{a}\right)(n)\end{array}$ & $\begin{array}{l}\text { Total number of } \\
\text { handled vials }(n)\end{array}$ & $\begin{array}{r}\text { Genotoxicity } \\
\text { (ratio to blank) }\end{array}$ \\
\hline 1 & Carboplatina) (4), Paclitaxel (2), Rituximab (1) & 4 & 7 & 0.97 \\
\hline 2 & 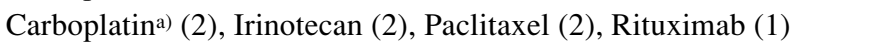 & 2 & 7 & 1.06 \\
\hline 3 & $\begin{array}{l}\text { Isophosphamide (2), Carboplatina) (9), Etoposidea) (2), } \\
\text { Irinotecan (2), Paclitaxel (3) }\end{array}$ & 11 & 18 & 3.93 \\
\hline 4 & Carboplatina) (5), Irinotecan (6), Vinorelbine (1), Rituximab (2) & 5 & 14 & 0.98 \\
\hline 5 & 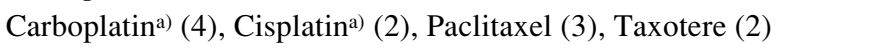 & 6 & 11 & 1.01 \\
\hline 6 & $\begin{array}{l}\text { Cyclophosphamide (11), Pirarubicina) (7), Carboplatina) (9), } \\
\text { Irinotecan (2), Paclitaxel (9), Taxotere (3), Vincristine (2) }\end{array}$ & 16 & 43 & 1.60 \\
\hline 7 & Carboplatin $^{\text {a) }}$ (4), Irinotecan (6), Paclitaxel (3) & 4 & 13 & 1.05 \\
\hline 8 & $\begin{array}{l}\text { Cyclophosphamide (17), Dacarbazinea) (4), Bleomycina) (1), } \\
\text { Doxorubicina) (3), Pirarubicina) }^{\text {a) }} \text { (12), Etoposidea) (1), Paclitaxel (3), } \\
\text { Vinblastine (1), Vincristine (4), Rituximab (1) }\end{array}$ & 21 & 47 & 1.75 \\
\hline
\end{tabular}

a)drugs confirmed to be genotoxic by the $u m u$ assay. 
Table 2. Characteristics of the exposed ${ }^{\text {a) }}$ and control $^{\text {b) }}$ groups

\begin{tabular}{lccc}
\hline & Exposed group (n=19) & Control group (n=18) & $p$ value \\
\hline Age (yr, Mean, Median, (Range)) & $29.2,28.0(21-48)$ & $31.6,32.0(21-47)$ & $\left.0.358^{\mathrm{c}}\right)$ \\
Duration of employment (yr, Mean, Median (Range)) & $5.7,4.2(0.2-25.2)$ & $7.2,3.7(0.2-29.2)$ & $0.775^{\mathrm{c})}$ \\
Employment experience in Roentgenology (workers, $\mathrm{n})$ & 0 & 6 & $0.008^{\mathrm{d})}$ \\
Smoker (workers, $\mathrm{n}$ ) & 3 & 2 & $1.000^{\mathrm{d})}$ \\
Alcohol consumer (workers, $\mathrm{n})$ & 10 & 8 & $0.746^{\mathrm{d})}$ \\
Undergoing treatment or taking Medicine (workers, $\mathrm{n})$ & 5 & 4 & $1.000^{\mathrm{d})}$ \\
\hline
\end{tabular}

a)exposed group consisted of female nurses who routinely prepared antineoplastic drugs. b)control group consisted of female nurses who did not prepare antineoplastic drugs. c)by Mann-Whitney's U-test. d)by Fisher's exact test.

Table 3. Lymphocyte DNA damage (tail length) in the alkaline method of the single cell gel electrophoresis assay

\begin{tabular}{|c|c|c|}
\hline \multicolumn{2}{|c|}{ Tail length, $\mu \mathrm{m}$, Mean, Median, (Range) } & \multirow{2}{*}{$\frac{p \text { value }^{\mathrm{a})}}{0.004}$} \\
\hline Exposed group $(n=19)$ & $8.8,8.5(4.5-13.6)$ & \\
\hline Control group $(n=18)$ & $6.0,5.1(3.5-10.3)$ & \\
\hline Exposed group except for smokers $(n=16)$ & $8.8,9.0(4.5-13.6)$ & 0.008 \\
\hline Control group except for smokers $(n=16)$ & $6.3,5.5(3.5-10.3)$ & \\
\hline Exposed group except for alcohol consumers $(n=9)$ & $9.6,9.6(6.2-13.6)$ & 0.028 \\
\hline Control group except for alcohol consumers $(n=10)$ & $6.9,5.9(4.7-10.3)$ & \\
\hline Exposed group except for nurses undergoing treatment or taking medicine $(n=14)$ & $8.8,8.5(4.5-13.6)$ & 0.008 \\
\hline Control group except for nurses undergoing treatment or taking medicine $(n=14)$ & $6.0,5.1(3.5-10.3)$ & \\
\hline Age below $29 \mathrm{yr}(\mathrm{n}=18)$ & $7.8,7.7(3.6-13.6)$ & 0.358 \\
\hline Age above 29 yr $(n=19)$ & $7.0,5.9(3.5-12.3)$ & \\
\hline Duration of employment below $4 \mathrm{yr}(\mathrm{n}=17)$ & $7.4,7.8(3.5-10.4)$ & 0.662 \\
\hline Duration of employment above $4 \mathrm{yr}(\mathrm{n}=20)$ & $7.3,6.1(3.6-13.6)$ & \\
\hline Smokers $(n=5)$ & $6.1,5.1 \quad(3.6-8.6)$ & 0.248 \\
\hline Non-smokers $(\mathrm{n}=32)$ & $7.6,7.7(3.5-13.6)$ & \\
\hline Alcohol consumers $(n=18)$ & $6.5,5.4(3.5-12.3)$ & 0.024 \\
\hline Teetotallers $(n=19)$ & $8.2,8.9(4.7-13.6)$ & \\
\hline Employment experience in roentgenology $(n=6)$ & $5.5,5.1 \quad(4.4-9.5)$ & 0.044 \\
\hline No employment experience in roentgenology $(n=31)$ & $7.7,7.8(3.6-13.6)$ & \\
\hline Control group: experience in roentgenology $(n=6)$ & $5.5,5.1 \quad(3.5-9.5)$ & 0.385 \\
\hline Control group: no experience in roentgenology $(n=12)$ & $6.4,5.5(3.6-10.3)$ & \\
\hline Control group: alcohol consumers $(n=8)$ & $5.1,4.7 \quad(3.5-9.3)$ & 0.034 \\
\hline Control group: teetotallers $(n=10)$ & $6.9,5.9(4.7-10.3)$ & \\
\hline
\end{tabular}

a)by Mann-Whitney's U-test.

respectively, with the difference being significant $(p=0.004)$. The median of the tail length for the exposed group was still significantly higher than for the control group when the smokers, alcohol consumers or the nurses who took medicine were excluded. The median tail lengths of individual nurses did not correlate with age, duration of employment or smoking. In all subjects, the median tail length of the nurses who had not had employment experience in roentgenology was higher than that of those who did, but in the control group, there was no difference. The median tail lengths of those who consumed alcohol was lower than that of the non- consumers, and this trend was also seen in the control group.

\section{Discussion}

To investigate work environment contamination by antineoplastic drugs in a hospital ward and the genotoxic risk exposed by it to nurses, the genotoxicity of the antineoplastic drugs used in a hospital ward and wipe samples of the workbench after handling of antineoplastic drugs were examined by the umu assay, and lymphocyte DNA damage was measured using the single cell gel electrophoresis assay. 
Eight of 19 antineoplastic drugs used in the hospital induced genotoxicity. The umu assay showed that almost all antibiotics and DNA chelators induced genotoxicity, while most plant alkaloids did not. The wipe samples showed genotoxicity on the three days when many vials of genotoxic drugs had been handled, showing leakage of the antineoplastic drugs onto the workbench. Thus, the nurses seemed to have been exposed to the drugs. To avoid exposure to antineoplastic drugs, compliance with the proper procedures for handling the drugs is needed ${ }^{15)}$. A syringe containing saline is needled into a vial, its piston is pulled in order to induce negative pressure in the vial. Then, the saline is injected into the vial. After the drug has been well dissolved, the solution is withdrawn from the syringe, the piston is pulled further to retain the negative pressure in the vial, and then the syringe is removed from the vial. However, this procedure cannot be adhered to when the number of vials increases, because the nurses must quickly handle the drugs. If negative pressure is not retained in the vial, aerosol of the drug is likely to leak from the vial when the syringe is removed from the vial, and the workbench would become contaminated by the antineoplastic drug. We used the umu assay to examine the wipe sample in this study, because the antineoplastic drugs handled varied from day to day in this ward and we wanted to evaluate the contamination of the work bench with a single assay method. However, this method does not measure the concentration of each drug, and if the workbench is contaminated by drugs which show negative in $u m u$ assay, the contamination cannot be detected. To investigate the contamination of each antineoplastic drug on the workbench, the direct measurement of each drug is needed. Furthermore, in order to accurately measure nurses' exposure to antineoplastic drugs, the monitoring of urinary drugs' concentrations is needed ${ }^{21)}$.

Our study showed that the median tail length of the exposed group was higher than that of the control group. Also the median tail length of the exposed group was still higher than that of the control group when smokers, alcohol consumers or the nurses who took medicine were excluded. Lymphocyte DNA damage was suggested to be induced by the exposure to antineoplastic drugs. Antineoplastic drug exposure of nurses may occur via various routes, inhalation, skin absorption and ingestion ${ }^{10)}$. A number of studies have indicated that antineoplastic drugs may cause increased genotoxic effects ${ }^{7-11}$. On the other hand, several studies have indicated no increase in the genotoxic effect ${ }^{12-14)}$. The possible variables to be discussed may include the drugs of concern, the exposure intensity, service duration and the method of occupational hygiene practice. In the present study, the protective equipment used by the nurses was only latex gloves, a mask, goggles or a gown were not worn, and a ventilated cabinet was absent. Because of these handling conditions, the nurses were considered to have been exposed to antineoplastic drugs, and their lymphocyte DNA damage had increased. To prevent occupational antineoplastic drug exposure, complete compliance with the guidelines, the use of safety equipment including gloves, masks, goggles and gowns, the spatial separation of the workbench, and the introduction of a safety cabinet are recommended. Sessink et al. reported that contamination was found not only on the workbench but also on the floors of different rooms and office desks ${ }^{22}$. In the present study, the workbench for handling antineoplastic drugs was near office desks and the outlet of an air conditioner, thus raising concerns about the exposure of other nurses to antineoplastic drugs. As for other characteristics, the median tail length of alcohol consumers was lower than that of non-consumers. Lymphocyte DNA damage was suggested to be increased by alcohol intake in leadexposed and rubber processing workers ${ }^{23,24)}$. Our findings differ from those results. In order to consider alcohol action on lymphocyte DNA damage, further epidemiological studies which investigate the relationship between alcohol intake and lymphocyte DNA damage are necessary. The median tail length of the nurses without employment experience in roentgenology seemed to be higher than that of those with this experience, but in the control group, there was no difference. The present study could not assess the genotoxicity of radiation. Medical staff occupationally exposed to radiation was reported to have a frequency of structural chromosome aberrations which was higher than that of unexposed group $^{25)}$.

In summary, contamination of the workbench was found when the nurses handled more drugs than on other days, and lymphocyte DNA damage was higher in nurses who handled antineoplastic drugs than in the control group. These findings suggest that the nurses had been exposed to the antineoplastic drugs and that lymphocyte DNA damage was increased by the exposure to antineoplastic drugs. However, in the present study, we could not completely remove the influence of possible confounders. In consideration of this limitation, further epidemiological studies which control confounders with multivariable analysis in larger scale populations are necessary. In the future, cancer chemotherapy will be performed at a specialist cancer chemotherapy center. Ishii et al. reported that the establishment rate of guidelines for the handling of antineoplastic drugs and the recognition of health effects from exposure to antineoplastic drugs at a specialist cancer chemotherapy center were high in comparison with a general hospital or an university hospital ${ }^{25}$. The genotoxic risk to nurses at a specialist cancer hospital has not been investigated. Further studies which investigate the contamination of the work environment and its genotoxic risks to nurses by type of hospital are needed. 


\section{References}

1) Black DJ and Livingston RB: Antineoplastic drugs in 1990: a review (Part 1). Drugs 39, 489-501 (1990)

2) Black DJ and Livingston RB: Antineoplastic drugs in 1990: a review (Part 2). Drugs 39, 652-673 (1990)

3) Morimoto S, Horisaka K, Kariya K. Pharmacology categorized by disorder. Tokyo: Hirokawa Publishing Co, 1996: 685-712.

4) International Agency for Research on Cancer. IARC monographs on the evaluation of carcinogenic risks to humans. Vol. 26: Some Antineoplastic and Immunosuppressive Agents. Lyon: IARC, 1981.

5) International Agency for Research on Cancer. IARC monographs on the evaluation of carcinogenic risks to humans. Vol. 76: Some Antiviral and Antineoplastic Drugs, and Other Pharmaceutical Agents. Lyon: IARC, 2000.

6) Sorsa M, Hemminki K and Vainio H: Occupational exposure to anticancer drug-potential and real hazards. Mutat Res 154, 135-149 (1985)

7) Falck K, Grohn P, Sorsa M, Vainio H, Heinonen E and Holsti LR: Mutagenicity in urine of nurses handling cytostatic drugs. Lancet 1, 1250-1251 (1979)

8) Thiringer G, Granung G, Holmen A, Hogstedt B, Jarvholm B, Jonsson D, Persson L, Wahlstrom J and Westin J: Comparison of methods for the biomonitoring of nurses handling antitumor drugs. Scand J Work Environ Health 17, 133-138 (1991)

9) Burgaz S, Karahalil B, Canhi Z, Terzioglu F, Ancel G, Anzion RB, Bos RP and Huttner E: Assessment of genotoxic damage in nurses occupationally exposed to antineoplastics by the analysis of chromosomal aberrations. Hum Exp Toxicol 21, 129-135 (2002)

10) Jakab MG, Major J and Tompa A: Follow-up genotoxicological monitoring of nurses handling antineoplastic drugs. J Toxicol Environ Health A 62, 307-318 (2001)

11) Undeger U, Basaran N, Kars A and Guc D: Assessment of DNA damage in nurses handling antineoplastic drugs by the alkaline COMET assay. Mutat Res 439, $277-$ 285 (1999)

12) Hessel H, Radon K, Pethran A, Maisch B, Grobmair S, Sautter I and Fruhmann G: The genotoxic risk of hospital, pharmacy and medical personnel occupationally exposed to cytostatic drugs-evaluation by the micronucleus assay. Mutat Res 497, 101-109 (2001)

13) DeMeo MP, Merono S, DeBaille AD, Botta A, Laget M, Guiraud H and Dumenil G: Monitoring exposure of hospital personnel handling cytostatic drugs and contaminated materials. Int Arch Occup Environ Health 66, 363-368 (1995)

14) Krepinsky A, Bryant DW, Davison L, Young B, Heddle $\mathrm{J}$, McCalla DR, Douglas $\mathrm{G}$ and Michalko K: Comparison of three assays for genetic effects of antineoplastic drugs on cancer patients and their nurses. Environ Mol Mutagen 15, 83-92 (1990)

15) Kitada M, Morikawa A, Katou H and Nakayama S. The revised version of guideline of handling antineoplastic drugs in medical center-Manual of handling antineoplastic drugs. Tokyo: Jiho Co, 2005.

16) Isii N, Dakeishi M, Sasaki M and Murata K: Safety awareness of anticancer drug handling among Japanese nurses. Jpn J Public Health 52, 727-735 (2005)

17) Oda $Y$, Nakamura S, Oki I, Kato T and Shinagawa H: Evaluation of the new system (umu-test) for the detection of environmental mutagens and carcinogens. Mutat Res 147, 214-229 (1985)

18) Ostling $\mathrm{O}$ and Johanson KJ: Microelectrophoretic study of radiation-induced DNA damages in individual mammalian cells. Biochem Biophys Res Commun 30, 291-298 (1984)

19) Maluf SW and Erdtmann B: Follow-up study of the genetic damage in lymphocytes of pharmacists and nurses handling antineoplastic drugs evaluated by cytokinesis-block micronuclei analysis and single cell gel electrophoresis assay. Mutat Res 471, 21-27 (2000)

20) Miller JH. Experiments in Molecular Genetics. NY: Cold Spring Harbor, 1972: 352-355.

21) Bos RP and Sessink PJ: Biomonitoring of occupational exposures to cytostatic anticancer drugs. Rev Environ Health 12, 43-58 (1997)

22) Sessink PJ, Boer KA, Scheefhals AP, Anzion RB and Bos RP: Occupational exposure to antineoplastic agents at several departments in a hospital. Environmental contamination and excretion of cyclophosphamide and ifosfamide in urine of exposed workers. Int Arch Occup Environ Health 64, 105-112 (1992)

23) Ye XB, Fu H, Zhu JL, Ni WM, Lu YW, Kuang XY, Yang SL and Shu BX: A study on oxidative stress in lead-exposed workers. J Toxicol Environ Health A 57, 161-172 (1999)

24) Zhu CQ, Lam TH, Jiang CQ, Wei BX, Xu QR, Chen YH: Increased lymphocyte DNA strand breaks in rubber workers. Mutat Res 470, 201-209 (2000)

25) Lalic H: Cytogenetic monitoring of medical staff professionally exposed to Gamma and $\mathrm{X}$ radiation. Neoplasma 52, 307-313 (2005) 